\title{
Correlation between ocular perfusion pressure and ocular pulse amplitude in glaucoma, ocular hypertension, and normal eyes
}

This article was published in the following Dove Press journal:

Clinical Ophthalmology

8 August 2013

Number of times this article has been viewed

Bruno P Figueiredo ${ }^{1,2}$

Sebastião Cronemberger'

Fabio N Kanadani ${ }^{3,4}$

'Departments of Ophthalmology, Federal University of Minas Gerais, Belo Horizonte, ${ }^{2}$ Departments of Ophthalmology, Glaucoma and

Cataract Service, Santa Casa of Belo Horizonte, ${ }^{3}$ Department of Ophthalmology, São José University Hospital, Belo Horizonte, Minas Gerais, ${ }^{4}$ Department of Ophthalmology, Federal University of São Paulo, São Paulo, Brazil
Correspondence: Bruno Pimentel Figueiredo Federal University of Minas Gerais, Av Contorno 4747, cj 35/36, Serra, 30I I0-090, Belo Horizonte MG, Brazil Tel + I 553| 32801800

Fax + I 553| 32801802

Email bruno@glaucoma.com.br
Background: The purpose of this study was to investigate the correlation between ocular perfusion pressure and ocular pulse amplitude in glaucoma, ocular hypertension, and normal eyes.

Methods: Ninety eyes from 90 patients were included. Thirty patients had been recently diagnosed with glaucoma and had no previous history of treatment for ocular hypotension, 30 had elevated intraocular pressure (IOP) without evidence of glaucoma, and 30 had normal IOP $(<21 \mathrm{mmHg})$ with no detectable glaucomatous damage. Goldmann applanation tonometry (GAT), dynamic contour tonometry (DCT), blood pressure measurement, pachymetry, Humphrey visual field, and routine ophthalmic examination was performed in each patient. Ocular perfusion pressure was calculated as the difference between mean arterial pressure and IOP. The ocular pulse amplitude was given by DCT. The Pearson correlation coefficient was used to compare the glaucomatous and ocular hypertensive groups, and comparisons with the normal IOP group were done using the Spearman's rank correlation coefficient.

Results: Mean IOP by DCT was $22.7 \pm 4.3 \mathrm{mmHg}$ in the glaucoma group, $22.3 \pm 2.8 \mathrm{mmHg}$ in the ocular hypertension group, and $14.3 \pm 1.6 \mathrm{mmHg}$ in the control group. Mean IOP by GAT was $19.0 \pm 5.1 \mathrm{mmHg}$ for glaucoma, $22.4 \pm 2.1 \mathrm{mmHg}$ for ocular hypertension, and $12.9 \pm 2.2 \mathrm{mmHg}$ for controls. Mean ocular pulse amplitude was $3.4 \pm 1.2 \mathrm{mmHg}$ in the glaucoma group, $3.5 \pm 1.2 \mathrm{mmHg}$ in the ocular hypertension group, and $2.6 \pm 0.9 \mathrm{mmHg}$ in the control group. Mean ocular perfusion pressure was $46.3 \pm 7.9 \mathrm{mmHg}$ in the glaucoma group, $46.3 \pm 7.9 \mathrm{mmHg}$ in the ocular hypertension group, and $50.2 \pm 7.0 \mathrm{mmHg}$ in controls No significant correlation between ocular perfusion pressure and ocular pulse amplitude was found in any of the groups $(P=0.865$ and $r=-0.032, P=0.403$ and $r=-0.156, P=0.082$ and $\rho=-0.307$ for glaucoma, ocular hypertension, and normal eyes, respectively).

Conclusion: There is no significant correlation between ocular perfusion pressure and ocular pulse amplitude values in glaucoma, ocular hypertension, or normal eyes. IOP values measured by GAT correlate with those measured by DCT.

Keywords: glaucoma, ocular pulse amplitude, ocular perfusion pressure, dynamic contour tonometry, vascular factors

\section{Introduction}

Chronic open-angle glaucoma is a multifactorial disorder of the optic nerve, and its main risk factor is elevated intraocular pressure (IOP). Current treatment for glaucoma focuses solely on reducing IOP, although some patients continue to progress even when IOP reaches the predetermined target level. Further, some individuals develop the disease at low IOP values, which is known as normal tension glaucoma. 
Therefore, it is reasonable to assume that risk factors other than IOP itself may contribute to the etiopathogenesis of glaucoma. Among these, vascular disorders, including atherosclerosis, migraine, Raynaud's phenomenon, and other vasospastic conditions, have been identified as potential risk factors for glaucoma. ${ }^{1-8}$

The influence of blood pressure (BP) as an independent risk factor for glaucoma remains controversial. Although some studies have shown a significant positive correlation between systemic hypertension and glaucoma, ${ }^{9,10}$ Leske et al found a negative correlation between these two variables. ${ }^{11}$ However, because BP and IOP tend to show circadian variation, their fluctuations may also be related to progression of glaucoma. ${ }^{12}$

A number of methods can be used to investigate the vascular factors related to glaucoma. One is to measure ocular perfusion pressure, reduction of which is suspected to be an important risk factor for glaucoma. ${ }^{13-15}$ Another way to assess the vascular component in glaucoma is to measure the ocular pulse amplitude by dynamic contour tonometry (DCT). ${ }^{16}$ The IOP varies according to the cardiac cycle, and this variation can be detected by rhythmic oscillation of the semicircles in Goldmann applanation tonometry (GAT). DCT measures the amplitude of the IOP variation between systole and diastole. ${ }^{17}$

The purpose of this study was to evaluate the correlation between ocular perfusion pressure and ocular pulse amplitude in glaucoma, ocular hypertension, and normal eyes.

\section{Materials and methods}

Ninety eyes from 90 patients were enrolled and divided into three groups. The glaucoma group included individuals recently diagnosed with the disease and no previous treatment. The ocular hypertension and normal groups had no identifiable functional and/or structural glaucoma damage indicated by IOP. The study was approved by the ethics committee of the Federal University of Minas Gerais, Brazil. Written informed consent was obtained from each participant. The research followed the tenets of the Declaration of Helsinki. Evaluation of the 90 patients was conducted by the same physician (BPF) during the period from September 2008 to May 2010.

The inclusion criteria were age older than 40 years, an open angle on gonioscopy, and best corrected visual acuity of $20 / 40$ or better. For a patient to be entered into the glaucoma group, coexistence of optic disc signs of glaucoma as well as damage in the visual field suggestive of glaucoma was necessary.

\section{Examination of optic nerve}

Evaluation of the optic disc and papillary retinal nerve fiber layer was done at slit-lamp examination using a 78 diopter lens. Identification of glaucomatous optic neuropathy was based on at least two of the following criteria: cup/disc ratio $>0.6$; localized rim loss in the superior or inferior quadrant; disc hemorrhage; and cup/disc asymmetry $>0.2 .^{11}$

\section{Examination of visual field}

The visual field was measured using a Humphrey field analyzer (Carl Zeiss Meditec Inc, Dublin, CA, USA) program 24-2 and the standard SITA strategy. Glaucoma damage was defined as the presence of at least two of the following criteria: a cluster of three or more nonedge points, all of which were depressed on the pattern deviation plot at a $P<0.05$ level and one of which was depressed at $P<0.01$ of normal fields; a glaucoma hemifield test outside normal limits; and pattern standard deviation at $P<0.05$ of normal fields. The visual field examination was repeated for each eye to check reproducibility of the findings, and if necessary, a third examination was performed within a week. In the event of incongruous data being obtained at the three examinations, the patient was excluded from the study. The criteria for reliability were: false positive $<33 \%$, false negative $<33 \%$, and fixation loss $<20 \%{ }^{18}$

\section{Goldmann applanation tonometry}

IOP was measured using a Goldmann applanation tonometer between 8 am and 9 am, always repeating the measurement within five minutes. In the event of the difference between the two values being less than $2 \mathrm{mmHg}$, the lower value was used. If the difference was greater than $2 \mathrm{mmHg}$, a third measurement was taken, and the lower value was to be considered, but still respecting the $2 \mathrm{mmHg}$ difference between measurements. In the event of a difference greater than $2 \mathrm{mmHg}$ between the three values, the patient was excluded from the study.

The individuals with ocular hypertension and the controls had none of the previously mentioned signs of glaucoma during examination of their optic nerve and/or visual field. Allocation to either of these two groups was based on the IOP value. The ocular hypertension group contained individuals with IOP $\geq 21 \mathrm{mmHg}$ and the control group contained those with IOP $<21 \mathrm{mmHg}$.

\section{Dynamic contour tonometry}

DCT readings were recorded using a Pascal tonometer (Swiss Microtechnology AG, Port, Switzerland) between 8 am and 9 
am. The quality of DCT measurement ranges from 1 to 5 (1 being optimal and 5 being least optimal), and only readings with quality levels of 1 and 2 were included in this study. Ocular pulse amplitude given by DCT represents the difference between systolic and diastolic IOP.

\section{Blood pressure}

BP was measured using a brachial sphygmomanometer (DS66, Welch Allyn, Skaneateles, NY, USA) and a Littmann Classic II stethoscope (3M, St Paul, MN, USA) on the upper right arm after the subject had been seated for at least 5 minutes. Caffeine, exercise, and smoking were not allowed for at least 30 minutes prior to examination. Two measurements were taken at 5 minute intervals and the average value recorded. ${ }^{19}$

\section{Ocular perfusion pressure}

By definition, perfusion pressure is calculated as follows: $\mathrm{PP}=\mathrm{MAP}-\mathrm{VP}$, where $\mathrm{PP}$ is perfusion pressure, MAP is mean arterial pressure, and VP is venous pressure. The MAP formula is: $\mathrm{MAP}=\mathrm{DBP}+[1 / 3 \times(\mathrm{SBP}-\mathrm{DBP})]$, where $\mathrm{PP}$ is perfusion pressure, $\mathrm{DBP}$ is diastolic blood pressure, and SBP is systolic blood pressure. To obtain the ocular perfusion pressure, one can use the perfusion pressure formula, substituting venous pressure for IOP. Because the blood pressure in the ophthalmic artery is $2 / 3$ of brachial BP, the final ocular perfusion pressure formula is as follows: ocular perfusion pressure $=2 / 3 \mathrm{MAP}-\mathrm{IOP}$.

\section{Gonioscopy and central corneal thickness}

Gonioscopy was performed using a Sussman lens (Ocular Inc, Dallas, TX, USA) and ultrasound pachymetry was performed using the DGH 555 device (DGH Technology Inc, Exton, PA, USA). Individuals with a previous history of glaucoma medication, ocular surgery, or laser procedures in the eye, a corneal disorder that could interfere with optimal GAT or DCT, spherical equivalent $> \pm 4.0 \mathrm{D}$, advanced cataract, or evidence of ocular infection were excluded from the study.

\section{Statistical analysis}

In the glaucoma group, the eye selected for statistical analysis was the one with lower cup/disc ratio, respecting the minimum 0.6 value. In the event of equal ratios in both eyes, the lower IOP eye was selected. If IOP was also the same, the right eye was used in the study. In the ocular hypertension group, the eye with the lower IOP was selected, respecting the $21 \mathrm{mmHg}$ value. In the event that the patient had the same IOP in both eyes, the right eye was selected. The right eye was always chosen in the normal group.

Univariate analysis was performed comparing ocular pulse amplitude and ocular perfusion pressure between the three groups using the $F$-test (analysis of variance) in the event of variables with a normal distribution. The Kruskal-Wallis test was used in the event of a non-normal distribution. Verification of distribution was performed using the Shapiro-Wilk test. When the $P$-value was significantly different between the three groups, a post hoc two on two comparisons was performed using either the Tukey range test (parametric) or the Mann-Whitney test with Bonferroni adjustment (nonparametric); the $P$-value for these two tests was 0.017 because there were three groups involved $(0.05 / 3)$.

To evaluate the relationship between ocular pulse amplitude (OPA) and ocular perfusion pressure, the Pearson correlation coefficient was calculated in the event of two variables having a normal distribution or Spearman rank's correlation coefficient if one of the variables had a nonnormal distribution. Statistical analysis was performed using R software version 2.14.1.

\section{Results}

The mean patient age was $57.2 \pm 9.9$ years in the glaucoma group, $49.9 \pm 8.7$ years in the ocular hypertension group, and $52.3 \pm 7.2$ years in the control group. There was a statistical difference between these mean ages when the three groups were compared ( $P=0.009$, Kruskal-Wallis test). A paired comparison between the groups showed a significant difference only when patients with glaucoma and those with ocular hypertension were compared $(P=0.005$, Mann-Whitney test/Bonferroni adjustment). Fifty-one subjects (56.7\%) were white, 30 (33.3\%) were "pardos" (ie, of mixed ethnicity), and nine (10\%) were of African descent. Forty-eight $(53.3 \%)$ men and $42(46.7 \%)$ women were included in the study. There were $18(60 \%)$ men in the glaucoma group, 14 (46.7\%) in the ocular hypertension group, and 16 (53.3\%) in the control group.

IOP was measured by GAT or DCT. Mean (standard deviation), median, and range values are shown in Table 1. The mean difference between the measurements obtained with the two techniques was $1.7 \mathrm{mmHg}$. Despite this difference, a high positive correlation was found when studying these two methods ( $r=0.832$ and $P<0.01$; Figure 1).

We also tested the correlation between each method of measuring IOP and central corneal thickness, and found a slight positive correlation between GAT and central corneal 
Table I Intraocular pressure by Goldmann applanation tonometry and dynamic contour tonometry

\begin{tabular}{lllll}
\hline IOP & $\mathbf{n}$ & Mean (SD) & Median & Range \\
\hline DCT & 90 & $19.8(5.0)$ & 19.7 & $10.2-31.9$ \\
$\quad$ Glaucoma & 30 & $22.7(4.3)$ & 23.2 & $13.7-31.9$ \\
Ocular hypertension & 30 & $22.3(2.8)$ & 22.2 & $16.6-27.9$ \\
Normal & 30 & $14.3(1.6)$ & 14.3 & $10.2-17.5$ \\
GAT & 90 & $18.1(5.2)$ & 20.0 & $10.0-30.0$ \\
Glaucoma & 30 & $19.0(5.1)$ & 20.5 & $10.0-30.0$ \\
Ocular hypertension & 30 & $22.4(2.1)$ & 22.0 & $21.0-27.0$ \\
Normal & 30 & $12.9(2.2)$ & 13.0 & $10.0-17.0$ \\
\hline
\end{tabular}

Note: All data are expressed in $\mathrm{mmHg}$.

Abbreviations: DCT, dynamic contour tonometry; GAT, Goldmann applanation tonometry; IOP, intraocular pressure; SD, standard deviation.

thickness $(r=0.230$ and $P=0.029)$, but no correlation between DCT and central corneal thickness $(r=-0.005$ and $P=0.965)$.

Mean (standard deviation) values for ocular pulse amplitude and perfusion pressure in the three groups are shown in Table 2. Ocular pulse amplitude ranged from $1.6 \mathrm{mmHg}$ to $6.4 \mathrm{mmHg}$ (glaucoma group), $0.9 \mathrm{mmHg}$ to $6.0 \mathrm{mmHg}$ (ocular hypertension group), and 0.9 to $4.9 \mathrm{mmHg}$ (in the group, Figure 2). The difference between the three groups was statistically significant $(P=0.002, F$ test). A Tukey range test was then used, and showed a significant difference between the glaucoma and control groups $(P=0.014)$ and between the ocular hypertension and control groups $(P=0.003)$. There was no statistically significant difference between the glaucoma and ocular hypertension groups $(P=0.887)$.

Ocular perfusion pressure ranged from $32.2 \mathrm{mmHg}$ to $63.8 \mathrm{mmHg}$ (glaucoma group), $27.1 \mathrm{mmHg}$ to $54.6 \mathrm{mmHg}$ (ocular hypertension group), and $37.3 \mathrm{mmHg}$ to $63.3 \mathrm{mmHg}$

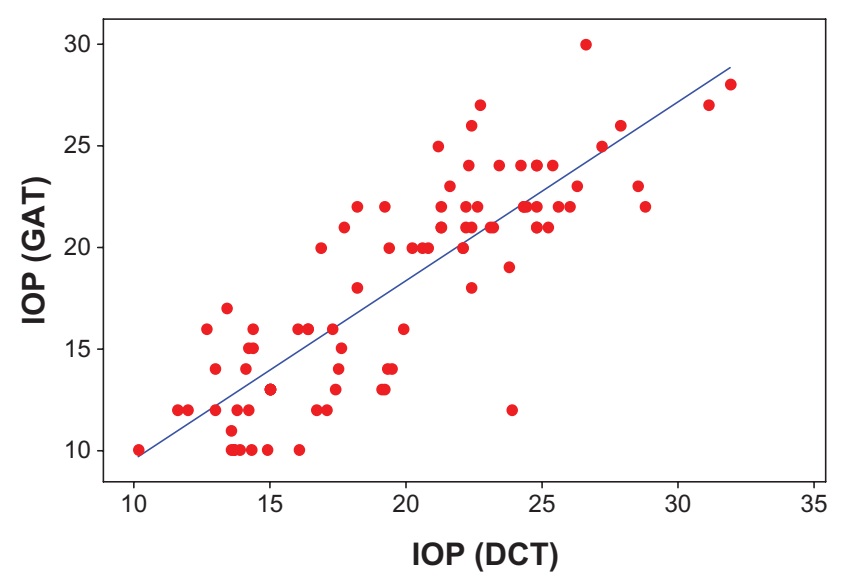

Figure I Relationship between intraocular pressure measured by Goldmann applanation tonometry and dynamic contour tonometry.

Abbreviations: IOP, intraocular pressure; DCT, dynamic contour tonometry; GAT, Goldmann applanation tonometry.
Table 2 Ocular pulse amplitude and ocular perfusion pressure in glaucoma, ocular hypertension, and normal eyes

\begin{tabular}{llllll}
\hline Group & \multicolumn{2}{l}{$\begin{array}{l}\text { Ocular pulse } \\
\text { amplitude }\end{array}$} & & \multicolumn{2}{l}{$\begin{array}{l}\text { Ocular perfusion } \\
\text { pressure }\end{array}$} \\
\cline { 2 - 3 } \cline { 5 - 6 } & Mean (SD) & P-value & & Mean (SD) & P-value \\
\hline $\begin{array}{l}\text { Glaucoma } \\
\text { Ocular }\end{array}$ & $3.4(I .2)$ & $0.002^{*}$ & & $46.3(7.9)$ & $<0.00 I^{* *}$ \\
$\begin{array}{l}\text { hypertension } \\
\text { Normal }\end{array}$ & $2.5(1.2)$ & & $4 I .5(5.2)$ & \\
\hline
\end{tabular}

Notes: *Statistically significant in F-test (analysis of variance); **statistically significant in Kruskal-Wallis test. All data are expressed in $\mathrm{mmHg}$. Abbreviation: SD, standard deviation.

(normal group, Figure 3). The Mann-Whitney test with Bonferroni adjustment was used to compare pairs of groups, and showed a significant difference between the glaucoma and ocular hypertension groups $(P=0.010)$ and between the ocular hypertension and control groups $(P<0.001)$. There was no statistically significant difference between the glaucoma and control groups $(P=0.026)$.

Systolic blood pressure was $131.0 \pm 16.7 \mathrm{mmHg}$ in the glaucoma group, $125.0 \pm 12.3 \mathrm{mmHg}$ in the ocular hypertension group, and $121.5 \pm 12.1 \mathrm{mmHg}$ in the control group, and diastolic blood pressure was $82.2 \pm 11.3 \mathrm{mmHg}$, $81.2 \pm 6.9 \mathrm{mmHg}$, and $81.5 \pm 9.0 \mathrm{mmHg}$, respectively.

Table 3 shows the correlation between ocular pulse amplitude and ocular perfusion pressure for the three groups. A significant correlation was not observed $(P>0.05)$ for these two variables between any of the three groups evaluated separately or when tested together.

\section{Discussion}

Accurate IOP measurement is critical in the diagnosis and treatment of patients with glaucoma. GAT has been the gold standard for measurement of IOP for over 50 years, although questions regarding its validity have arisen since

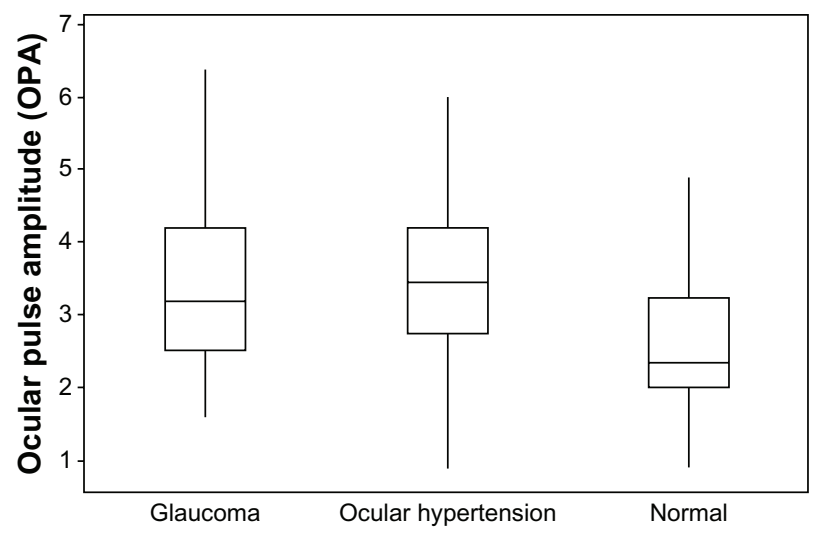

Figure 2 Mean ocular pulse amplitude in glaucoma, ocular hypertension, and normal eyes. 


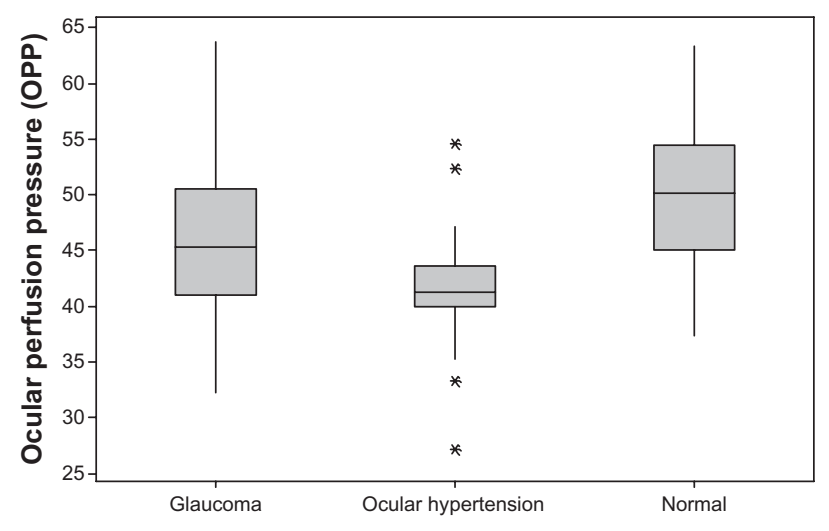

Figure 3 Mean ocular perfusion pressure in glaucoma, ocular hypertension, and normal eyes. *Denotes outliers.

publication of the Ocular Hypertensive Treatment Study and European Glaucoma Progression Study, both of which identified a relationship between corneal central thickness and IOP. ${ }^{20}$ Other studies have confirmed the influence of corneal properties and biomechanics on IOP measured by GAT. ${ }^{21-24}$ DCT is an alternative way to measure IOP, and is based on a completely new physical principle that does not distort the corneal anatomy. ${ }^{16}$ Therefore, DCT seems to be less affected by factors such as corneal thickness and hysteresis when compared with GAT. ${ }^{25}$ In our study, the difference between mean measurements taken on DCT and GAT was $1.7 \mathrm{mmHg}$. A similar difference has been observed in other studies, ranging from $0.7 \mathrm{mmHg}$ to $2.8 \mathrm{mmHg}$. A positive correlation between DCT and GAT is also reported in the literature, as well as in the present study. ${ }^{26-33}$ Doyle and Lachkar ${ }^{28}$ reported a study showing that individuals with normal or high central corneal thickness had similar IOP values on GAT and DCT, and that IOP values for a thin cornea tended to show a higher discrepancy between the two measurements, possibly due to underestimation of IOP by the Goldmann tonometer. DCT measurements tend to be less influenced by central corneal thickness than measurements obtained on GAT, ${ }^{27,28,34,35}$ especially in individuals with thin corneas.

Table 3 Correlation between ocular perfusion pressure and ocular pulse amplitude

\begin{tabular}{lll}
\hline Ocular perfusion pressure & \multicolumn{2}{l}{ Ocular pulse amplitude } \\
\cline { 2 - 3 } & Coefficient & $P$-value \\
\hline Patient groups & -0.032 & $0.865^{*}$ \\
Glaucoma & -0.156 & $0.403^{*}$ \\
Ocular hypertension & -0.307 & $0.082^{* *}$ \\
Normal &
\end{tabular}

Notes: *Statistically significant Pearson correlation coefficient and **statistically significant Spearman correlation coefficient.
Another advantage of DCT is that it measures IOP in a continuous manner, and so captures variation in IOP during the cardiac cycle. ${ }^{16}$ The rhythmic oscillation of IOP is measured by DCT and presented as the ocular pulse amplitude. The role of ocular pulse amplitude in glaucoma is still unclear. Weizer et al published a study correlating ocular pulse amplitude with severity of glaucoma, and concluded that a high ocular pulse amplitude seems to be related to less severe glaucoma. ${ }^{30}$ Schwenn et al showed that a low ocular pulse amplitude was more likely to be present in normal tension glaucoma than in primary open angle glaucoma, ocular hypertension, or normal eyes. ${ }^{36}$ Kynigopoulos et al found a relationship between low ocular pulse amplitude and presence of functional and structural damage in primary open angle glaucoma. ${ }^{37}$ In our study, the mean ocular pulse amplitude was significantly lower in the control group than in the glaucoma or ocular hypertension groups. A possible reason for this is the positive correlation between GAT and ocular pulse amplitude, as explained by Punjabi et a $\mathrm{l}^{38}$ and Kaufmann et al..$^{39}$ In our study, we did not use high IOP ( $>21$ $\mathrm{mmHg}$ ) as an inclusion criterion for the glaucoma group. Therefore, the mean IOP in the ocular hypertensive group was higher than in the glaucoma patients.

According to the ocular perfusion pressure formula, one has low ocular perfusion pressure when blood pressure is relatively low and IOP is relatively high. A number of population-based epidemiologic studies have demonstrated a relationship between low ocular perfusion pressure and glaucoma. ${ }^{11,13,40-42}$ There is no consensus on a reference value to differentiate between normal and altered ocular perfusion pressure. Leske et al found that ocular perfusion pressure $<42 \mathrm{mmHg}$ was associated with a higher risk of developing glaucoma (relative risk 2.2). ${ }^{11}$ In the present study, the normal group had a mean ocular perfusion pressure ranging from $43.2 \mathrm{mmHg}$ to $57.2 \mathrm{mmHg}$, ie, above the cutoff value of $42 \mathrm{mmHg}$ proposed on the basis of the results from the Barbados study. ${ }^{11}$ In the ocular hypertension group, we found a low mean ocular perfusion pressure that could be explained by a high mean IOP and the fact that ocular perfusion pressure and IOP are inversely proportional. We assumed that ocular perfusion pressure was higher in our glaucoma group because we did not include only glaucoma patients with high IOP.

Assessment of ocular blood flow using ocular perfusion pressure and/or ocular pulse amplitude can be rather limited for two main reasons. First, fluctuation in measurements, especially at night, when blood pressure drops dramatically, can occur in patients defined as nonphysiologic dippers, 
leading to poor perfusion of the optic nerve. ${ }^{43,45}$ Also, both ocular perfusion pressure and ocular pulse amplitude are more related to IOP itself than any other factor that could directly influence ocular blood flow. The association between vascular risk factors, including ocular perfusion pressure and ocular pulse amplitude, in glaucoma has been the subject of several recent studies, all of which showed no significant correlation between these two vascular factors. ${ }^{46,47}$ Ocular perfusion pressure and ocular pulse amplitude may have independent roles in the three types of patients included in this study. Systemic vascular regulation as well as the impact of treatment on systemic disorders must also affect patients in an independent manner. There is still much to learn about the complex interaction between these factors.

\section{Conclusion}

In conclusion, our results show no correlation between ocular perfusion pressure and ocular pulse amplitude in glaucoma, ocular hypertension, or normal eyes. We found a strong correlation between GAT and DCT. Corneal thickness was slightly related to GAT and not related to DCT.

\section{Disclosure}

The authors report no conflicts of interest in this work.

\section{References}

1. Drance SM, Douglas GR, Wijsman K, et al. Response of blood flow to warm and cold in normal and low-tension glaucoma patients. Am J Ophthalmol. 1988;105:35-39.

2. Gasser P, Flammer J. Blood-cell velocity in the nailfold capillaries of patients with normal-tension and high-tension glaucoma. Am J Ophthalmol. 1991;111:585-588.

3. Phelps CD, Corbett JJ. Migraine and low-tension glaucoma. A casecontrol study. Invest Ophthalmol Vis Sci. 1985;26:1105-1108.

4. Goldberg I, Hollows FC, Kass MA, et al. Systemic factors in patients with low-tension glaucoma. Br J Ophthalmol. 1981;65:56-62.

5. Waldmann E, Gasser P, Dubler B, et al. Silent myocardial ischemia in glaucoma and cataract patients. Graefes Arch Clin Exp Ophthalmol. 1996;234:595-598.

6. François J, Neetens A. The deterioration of the visual field in glaucoma and the blood pressure. Doc Ophthalmol. 1970;28:70-132.

7. Drance SM. The concept of chronic open-angle glaucoma: a personal view. Ophthalmologica. 1996;210:251-256.

8. Hayreh SS, Zimmerman MB, Podhajsky P, et al. Nocturnal arterial hypotension and its role in optic nerve head and ocular ischemic disorders. Am J Ophthalmol. 1994;117:603-624.

9. Mitchell P, Lee AJ, Rochtchina E, et al. Open-angle glaucoma and systemic hypertension: the Blue Mountains Eye Study. J Glaucoma. 2004;13:319-326.

10. Ulrich A, Ulrich C, Barth T, et al. Detection of disturbed autoregulation of the peripapillary choroid in primary open angle glaucoma. Ophthalmic Surg Lasers. 1996;27:746-757.

11. Leske MC, Wu S-Y, Hennis A, et al. Risk factors for incident openangle glaucoma: the Barbados Eye Studies. Ophthalmology. 2008;115: $85-93$.
12. Demailly P, Cambien F, Plouin PF, et al. Do patients with low tension glaucoma have particular cardiovascular characteristics? Ophthalmologica. 1984;188:65-75.

13. Tielsch JM, Katz J, Sommer A, et al. Hypertension, perfusion pressure, and primary open-angle glaucoma. A population-based assessment. Arch Ophthalmol. 1995;113:216-221.

14. Weinreb RN, Harris A, editors. Ocular Blood Flow in Glaucoma. Amsterdam, The Netherlands: Kugler Publications; 2009.

15. Hayreh SS. Blood flow in the optic nerve head and factors that may influence it. Prog Retin Eye Res. 2001;20:595-624.

16. Kanngiesser HE, Kniestedt C, Robert YC. Dynamic contour tonometry: presentation of a new tonometer. J Glaucoma. 2005;14:344-350.

17. McKee HD, Saldaña M, Ahad MA. Increased ocular pulse amplitude revealing aortic regurgitation. Am J Ophthalmol. 2004;138:503.

18. Mills RP, Budenz DL, Lee PP, et al. Categorizing the stage of glaucoma from pre-diagnosis to end-stage disease. Am J Ophthalmol. 2006;141: 24-30.

19. Chobanian AV, Bakris GL, Black HR, et al. Seventh Report of the Joint National Committee on Prevention, Detection, Evaluation, and Treatment of High Blood Pressure. Hypertension. 2003;42: $1206-1252$.

20. Brandt JD. Corneal thickness in glaucoma screening, diagnosis, and management. Curr Opin Ophthalmol. 2004;15:85-89.

21. Detry-Morel M, Jamart J, Detry MB, et al. Clinical evaluation of the Pascal dynamic contour tonometer. J Fr Ophtalmol. 2007;30:260-270. French.

22. Hager A, Annette H, Loge K, et al. Effect of central corneal thickness and corneal hysteresis on tonometry as measured by dynamic contour tonometry, ocular response analyzer, and Goldmann tonometry in glaucomatous eyes. J Glaucoma. 2008;17:361-365.

23. Morita T, Shoji N, Kamiya K, et al. Intraocular pressure measured by dynamic contour tonometer and ocular response analyzer in normal tension glaucoma. Graefes Arch Clin Exp Ophthalmol. 2010;248: 73-77.

24. Kara N, Bozkurt E, Baz O, et al. Corneal biomechanical properties and intraocular pressure measurement in Marfan patients. $J$ Cataract Refract Surg. 2012;38:309-314.

25. Mangouritsas G, Mourtzoukos S, Mantzounis A, et al. Comparison of Goldmann and Pascal tonometry in relation to corneal hysteresis and central corneal thickness in nonglaucomatous eyes. Clin Ophthalmol. 2011;5:1071-1077.

26. Kaufmann C, Bachmann LM, Thiel MA. Comparison of dynamic contour tonometry with Goldmann applanation tonometry. Invest Ophthalmol Vis Sci. 2004;45:3118-3121.

27. Kotecha A, White ET, Shewry JM, et al. The relative effects of corneal thickness and age on Goldmann applanation tonometry and dynamic contour tonometry. Br J Ophthalmol. 2005;89:1572-1575.

28. Doyle A, Lachkar Y. Comparison of dynamic contour tonometry with Goldman applanation tonometry over a wide range of central corneal thickness. J Glaucoma. 2005;14:288-292.

29. Schneider E, Grehn F. Intraocular pressure measurement - comparison of dynamic contour tonometry and Goldmann applanation tonometry. J Glaucoma. 2006;15:2-6.

30. Weizer JS, Asrani S, Stinnett SS, et al. The clinical utility of dynamic contour tonometry and ocular pulse amplitude. J Glaucoma. 2007;16:700-703.

31. Lee J, Lee CH, Choi J, et al. Comparison between dynamic contour tonometry and Goldmann applanation tonometry. Korean J Ophthalmol. 2009;23:27-31.

32. Kotecha A, White E, Schlottmann PG, et al. Intraocular pressure measurement precision with the Goldmann applanation, dynamic contour, and ocular response analyzer tonometers. Ophthalmology. 2010;117:730-737.

33. Ito K, Tawara A, Kubota T, et al. IOP measured by dynamic contour tonometry correlates with IOP measured by Goldmann applanation tonometry and non-contact tonometry in Japanese individuals. J Glaucoma. 2012;21:35-40. 
34. Sáenz-Francés F, García-Catalán R, Jerez-Fidalgo M, et al. Comparison of Goldmann applanation and dynamic contour tonometry measurements: Effects of corneal morphometry. Arch Soc Esp Oftalmol. 2011;86:287-291. Spanish.

35. Francis BA, Hsieh A, Lai MY, et al. Effects of corneal thickness, corneal curvature, and intraocular pressure level on Goldmann applanation tonometry and dynamic contour tonometry: Los Angeles Latino Eye Study Group. Ophthalmology. 2007;114:20-26.

36. Schwenn O, Troost R, Vogel A, et al. Ocular pulse amplitude in patients with open angle glaucoma, normal tension glaucoma, and ocular hypertension. Br J Ophthalmol. 2002;86:981-984.

37. Kynigopoulos M, Tzamalis A, Ntampos K, et al. Decreased ocular pulse amplitude associated with functional and structural damage in open-angle glaucoma. Eur J Ophthalmol. 2012;22:111-116.

38. Punjabi OS, Ho HK, Kniestedt C, et al. Intraocular pressure and ocular pulse amplitude comparisons in different types of glaucoma using dynamic contour tonometry. Curr Eye Res. 2006;31:851-862.

39. Kaufmann C, Bachmann LM, Robert YC, et al. Ocular pulse amplitude in healthy subjects as measured by dynamic contour tonometry. Arch Ophthalmol. 2006;124:1104-1108.

40. Bonomi L, Marchini G, Marraffa M, et al. Vascular risk factors for primary open angle glaucoma: the Egna-Neumarkt study. Ophthalmology. 2000;107:1287-1293.
41. Quigley HA, West SK, Rodriguez J, et al. The prevalence of glaucoma in a population-based study of Hispanic subjects: Proyecto VER. Arch Ophthalmol. 2001;119:1819-1826.

42. Hulsman CA, Vingerling JR, Hofman A, et al. Blood pressure, arterial stiffness, and open-angle glaucoma: the Rotterdam study. Arch Ophthalmol. 2007;125:805-812.

43. Collignon N, Dewe W, Guillaume S, et al. Ambulatory blood pressure monitoring in glaucoma patients. The nocturnal systolic dip and its relationship with disease progression. Int Ophthalmol. 1998;22: 19-25.

44. Detry M, Boschi A, Ellinghaus G, et al. Simultaneous 24-hour monitoring of intraocular pressure and arterial blood pressure in patients with progressive and non-progressive primary open-angle glaucoma. Eur J Ophthalmol. 1996;6:273-278.

45. Tokunaga T, Kashiwagi K, Tsumura T, et al. Association between nocturnal blood pressure reduction and progression of visual field defect in patients with primary open-angle glaucoma or normal-tension glaucoma. Jpn J Ophthalmol. 2004;48:380-385.

46. Choi J, Lee J, Park SB, et al. Factors affecting ocular pulse amplitude in eyes with open angle glaucoma and glaucoma-suspect eyes. Acta Ophthalmol. 2012;90:552-558.

47. Gugleta K, Polunina A, Kochkorov A, et al. Association between risk factors and glaucomatous damage in untreated primary open-angle glaucoma. J Glaucoma. January 20, 2012. [Epub ahead of print.]
Clinical Ophthalmology

\section{Publish your work in this journal}

Clinical Ophthalmology is an international, peer-reviewed journal covering all subspecialties within ophthalmology. Key topics include: Optometry; Visual science; Pharmacology and drug therapy in eye diseases; Basic Sciences; Primary and Secondary eye care; Patien Safety and Quality of Care Improvements. This journal is indexed on

Submit your manuscript here: http://www.dovepress.com/clinical-ophthalmology-journal

\section{Dovepress}

PubMed Central and CAS, and is the official journal of The Society of Clinical Ophthalmology (SCO). The manuscript management system is completely online and includes a very quick and fair peer-review system, which is all easy to use. Visit http://www.dovepress.com/ testimonials.php to read real quotes from published authors. 